\title{
Reinduction Therapy
}

National Cancer Institute

\section{Source}

National Cancer Institute. Reinduction Therapy. NCI Thesaurus. Code C158877.

Treatment administered after a relapse of cancer. 